\title{
Digital screen time during the COVID-19 pandemic: a public
}

\section{health concern [version 1; peer review: 1 approved, 1}

\section{approved with reservations]}

\author{
Abida Sultana1-3, Samia Tasnim (101,2,4, Md Mahbub Hossain1,2,4, \\ Sudip Bhattacharya ${ }^{5}$, Neetu Purohit 6 \\ ${ }^{1}$ Nature Study Society of Bangladesh, Khulna, Bangladesh \\ 2EviSyn Health, Khulna, Bangladesh \\ ${ }^{3}$ Gazi Medical College, Khulna, Bangladesh \\ ${ }^{4}$ Texas A\&M University System, College Station, Tx, 77840, USA \\ ${ }^{5}$ Himalayan Institute of Medical Sciences, Dehradun, India \\ ${ }^{6}$ IIHMR University, Jaipur, India
}

\author{
V1 First published: $08 \mathrm{Feb} 2021$, 10:81 \\ https://doi.org/10.12688/f1000research.50880.1 \\ Latest published: 08 Feb 2021, 10:81 \\ https://doi.org/10.12688/f1000research.50880.1
}

\begin{abstract}
Due to the restrictions imposed to contain the coronavirus disease 2019 (COVID-19) pandemic, different population groups have adapted to varying screen time levels, which may have profound implications on their physical and mental wellbeing. Several empirical studies included in this review reported a sudden upward change in screen time across different population groups. A higher number of people with increased screen time compared to their pre-pandemic state and prolonged duration of total screen time substantiates such assertions. The available evidence suggests that screen time is associated with obesity, hypertension, type 2 diabetes, myopia, depression, sleep disorders, and several non-communicable diseases. This elevated burden of diseases is more prevalent among individuals who have sedentary lifestyles and other unhealthy behaviors that are likely to increase during quarantine or isolation due to COVID-19. Hence, it is critical to assess the adverse health outcomes that may appear as long-term consequences of such behavior. Researchers and practitioners need to revisit the available guidelines and incorporate evidence-based interventions for preventing unhealthy screen time among the affected individuals. Such interventions may address harmful behaviors associated with screen time and promote active lifestyles that may improve health across populations during and after this pandemic.
\end{abstract}

Keywords

Screen time; Screen use; COVID-19; Coronavirus; Health promotion.

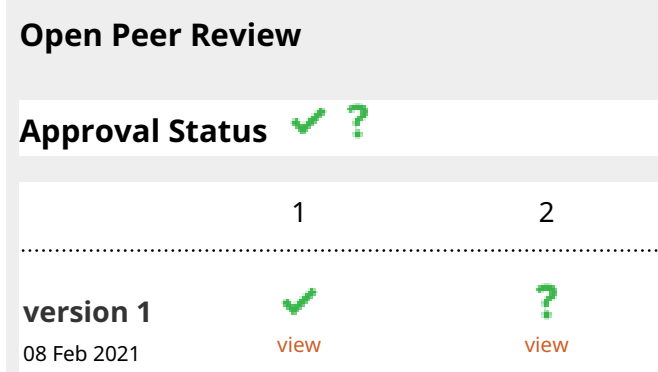

1. Michael Johnson Jr. ID , California State University, Northridge, USA

2. Sukhpreet Tamana (D), Simon Fraser

University, Burnaby, Canada

Victor Ezeugwu, University of Alberta,

Edmonton, Canada

Any reports and responses or comments on the article can be found at the end of the article. 
This article is included in the Coronavirus

collection.

Corresponding author: Samia Tasnim (tasnim@tamu.edu)

Author roles: Sultana A: Conceptualization, Data Curation, Investigation, Project Administration, Resources, Supervision, Writing Original Draft Preparation, Writing - Review \& Editing; Tasnim S: Conceptualization, Investigation, Project Administration, Writing Original Draft Preparation, Writing - Review \& Editing; Hossain MM: Conceptualization, Data Curation, Methodology, Project Administration, Resources, Supervision, Writing - Original Draft Preparation, Writing - Review \& Editing; Bhattacharya S: Conceptualization, Methodology, Resources, Writing - Original Draft Preparation, Writing - Review \& Editing; Purohit N: Investigation, Methodology, Resources, Writing - Original Draft Preparation, Writing - Review \& Editing

Competing interests: No competing interests were disclosed.

Grant information: The author(s) declared that no grants were involved in supporting this work.

Copyright: (c) 2021 Sultana A et al. This is an open access article distributed under the terms of the Creative Commons Attribution License, which permits unrestricted use, distribution, and reproduction in any medium, provided the original work is properly cited.

How to cite this article: Sultana A, Tasnim S, Hossain MM et al. Digital screen time during the COVID-19 pandemic: a public health concern [version 1; peer review: 1 approved, 1 approved with reservations] F1000Research 2021, 10:81

https://doi.org/10.12688/f1000research.50880.1

First published: 08 Feb 2021, 10:81 https://doi.org/10.12688/f1000research.50880.1 


\section{Introduction}

The coronavirus disease 2019 (COVID-19) pandemic has critically impacted physical and mental health globally ${ }^{1,2}$. Many countries have adopted varying measures to minimize the transmission of the disease, including adopting shelter in place policies, staying at home, limiting access to nursing homes, and prohibiting gatherings at places where people can potentially come into closer contact ${ }^{3}$. Populations with stricter preventive strategies, higher contact tracing, and faster clinical care may result in better public health outcomes during this pandemic ${ }^{4-6}$. However, the closure or remote operations of schools, offices, and other organizations have resulted in higher use of digital media such as desktops, laptops, tablet computers, and mobile devices for interpersonal communications and other organizational activities $^{7,8}$. People staying at home or closed places spend higher hours watching television or using digital media for entertainment purposes $^{9}$. Previous research shows that screen time is associated with a wide range of non-communicable diseases among vulnerable individuals ${ }^{10-13}$. Recent empirical studies suggest a rapid increase in digital screen time in different populations during the COVID-19 pandemic ${ }^{14-17}$. This necessitates a comprehensive understanding of the potential public health impacts and how preventive strategies should be adopted to address these.

In this narrative literature review, we aimed to describe the epidemiological burden of prolonged screen time and associated problems in COVID-19 from available articles retrieved from Medline and Google Scholar using a non-systematic approach. It was not possible to conduct a systematic literature review due to the low number of empirical research articles. The epidemiological burden is primarily described as the prevalence and the average duration of screen time of the individuals or population studied. Secondarily, key factors associated with these problems are summarized to inform the risk and protective factors. Lastly, we have discussed how the current evidence may inform future research, policy development and practice, to improve screen-based behaviors amid the COVID-19 pandemic and future public health emergencies.

\section{Discussion}

\section{COVID-19 and rising trends of screen time: public} health concerns

A growing body of literature concerns the rising trends of screen time and its associated health outcomes during the COVID-19 pandemic. A study of 254 Canadian families with young children reported increased screen time in mothers, fathers, and children during COVID-19 at 74\%, 61\%, and 87\%, respectively ${ }^{17}$. Moreover, a study conducted in China found that about $70 \%$ of 1033 participants spent more time looking at screens after the COVID-19 outbreak ${ }^{16}$. Another study used a longitudinal design to evaluate health behavior changes during COVID-19 and found a perceived increase in screen time among the participants ${ }^{15}$. Furthermore, a study conducted in Poland reported that $49 \%$ of the participants experienced an elevated screen time during the COVID-19 pandemic ${ }^{14}$. Additionally, a study conducted in Turkey during the final days of the long-standing lockdown found that nearly $72 \%$ of the children studied had a higher screen time compared to the previous years ${ }^{18}$. In that group, the average duration of screen time was 6.4 hours per day, which is much higher than the 2 hours per day recommendations of the American Academy of Child and Adolescent Psychiatry $(\mathrm{AACAP})^{18}$. Another study recruited 4108 participants from nine European countries and found a $65 \%$ increased screen time among the participants during this pandemic ${ }^{19}$. According to the survey conducted by Majumder et al., among 203 Indian day job holders and university students, the use of electronic devices such as televisions, computers and cell phones has increased significantly during the lockdown phase ${ }^{20}$. These studies provide early evidence on rising trends of screen time in diverse populations, which necessitate an investigation into how such trends may impact public health in the global scenario.

A study from the UK found that the participants had an average of 7.2 hours of screen time, which was higher in younger adults aged below 34 years compared to those aged 65 years or above ${ }^{21}$. This study reported a positive association between screen time and poor mental health among the participants ( $\mathrm{OR}=1.07,95 \% \mathrm{CI}=1.02-1.13)$, which was more significant in women $(\mathrm{OR}=1.07,95 \% \mathrm{CI}=1.01-1.14)$ and adults aged 35-64 years $(\mathrm{OR}=1.13$, 95\% $\mathrm{CI}=1.05-1.22)$. Another largescale study from China conducted among more than 12,000 participants from all central provinces reported that the average screen time was more than 4 hours per day while they were staying at home. They also found that individuals with more strenuous physical activities had a better emotional state and lesser screen time than those with lighter physical activity ${ }^{22}$. A study from Canada reported that men and women had better general and mental health status if they had an active lifestyle with lesser screen time compared to those who had a sedentary lifestyle with higher screen time ${ }^{23}$. Xiao and colleagues surveyed 1680 Chinese adolescents and reported that screen time was negatively associated with $\operatorname{mood}^{24}$. Additionally, children with lesser screen time and increased physical activity had a reduced number of conflicts with their parents ${ }^{24}$. The available evidence confirms that the early impacts of screen time on different age groups can range from physical to psychosocial conditions with varying risks, which may require longitudinal studies focusing on the relationships between screen time and the multiple variables that may explain the causality, as well as the long-term consequences of screen time.

The current evidence on adverse health outcomes associated with increased screen time may require an ecological evaluation by expanding the focus on correlated factors such as dietary practices and physical activities among the affected population. For example, Pišot and colleagues reported an increased body mass that could be explained by meal sizes, unhealthy food consumption, sports time, and screen time ${ }^{19}$. Similarly, Górnicka found that $43 \%$ of respondents had experienced a reduction in physical activity, and 34\% had increased food consumption in a sample where $49 \%$ of individuals reported an increased screen time ${ }^{14}$. A study from China assessed the physical and psychosocial health impacts of the nationwide lockdown and found that more than half of Chinese adults had a sedentary lifestyle with inadequate physical activity, increased screen time, and poor emotional state ${ }^{16}$. These studies suggest that a synergistic effect 
may exist between these co-occurring health behaviors, which can be prevalent among individuals affected by this pandemic. Screen time alone or in combination with other sedentary behaviors may have detrimental effects on populations affected by COVID-19, which should be examined in the context of global evidence from previous research on screen time and associated health outcomes.

\section{Global evidence on the association between screen time and health outcomes}

Global evidence suggests that screen time is associated with multiple health outcomes in different population groups. Syntheses of primary studies summarized in numerous systematic reviews and meta-analyses may provide a more substantial evidence base on a health problem of interest ${ }^{25-27}$. Multiple studies have shown adverse ophthalmological impacts associated with screen time. A meta-analytic review of 15 studies found a pooled odds ratio (OR) for myopia of 1.02 (95\% confidence interval $[\mathrm{CI}]: 0.96-1.08)$ in a sample of 49789 children $^{13}$. A significant proportion of evidence-based reviews report higher risks of non-communicable diseases associated with screen time. For example, a meta-analysis of 16 studies found that the odds of overweight or obesity was 1.67 (95\% CI: $1.48-1.88, \mathrm{P}<.0001)$ in children who had screen time $\geq 2$ hours per day ${ }^{28}$. A doseresponse meta-analysis found linear associations between television viewing and type 2 diabetes and hypertension and a non-linear association with overweight or obesity among adult participants ${ }^{29}$. This study also reported that each added hour of television viewing increased the risks of hypertension and type 2 diabetes by $6 \%$ and $8 \%$, respectively ${ }^{29}$.

Moreover, the risks of non-communicable diseases associated with sedentary activities that increase screen time may provide critical insights into how screen time can be prevalent alongside other health behavior and yield poor health outcomes across population groups. A large hospital-based cohort study confirmed a direct deleterious relationship between screen time and cardiovascular disease (CVD) events and all-cause mortality ${ }^{30}$. It indicated individuals who engaged in screen-based entertainment for more than 4 hours per day were at 1.5 times higher risk of all-cause mortality and 2.3 times increased risk of clinically confirmed CVD events compared to those with less than 2 hours of screen time per day ${ }^{30}$. A meta-analysis of 20 studies analyzed 32 effect sizes on the relationship between non-active video gaming and body mass ${ }^{31}$. This study found a positive relationship between these two constructs, whereas moderator analyses revealed that the relationship was pronounced among adults compared to children or adolescents.

Several evidence-based reviews have reported the mental health impacts of elevated screen time. For example, another meta-analytic review of 12 cross-sectional and seven longitudinal studies found that individuals with higher screen time had significantly elevated risks of depression (OR: 1.28, 95\% CI: $1.17-1.39, \mathrm{p}<.01)^{10}$. Another review of 31 studies reported that screen time was associated with poorer sleep outcomes in infants, toddlers, and preschoolers ${ }^{11}$. Such psychosocial health outcomes associated with screen time may not depend on the quantity of time using the screen, only the quality and contents of screen use may critically impact individuals. A meta-analytic review of 43 studies with a sample of 31,162 participants found that mass trauma television coverage was associated with acute stress reactions and posttraumatic stress outcomes, highlighting the psychosocial implications of television content for the users of this media ${ }^{32}$. These evidence-based reviews may enable reflection on how the pattern of screen time in the current pandemic may be associated with multiple health outcomes globally.

\section{Mitigating adverse health outcomes associated with screen time during COVID-19}

Contemporary evidence suggests a rapid increase in digital screen time during the COVID-19 pandemic. In contrast, pre-pandemic research syntheses indicate that such incremental use of screen-based media may result in adverse physical and mental health consequences in the affected populations. Such challenges may impose an added burden of non-communicable diseases globally in the post-pandemic world. It is critical to acknowledge this upcoming public health crisis and adopt mitigation strategies to prevent the health hazards associated with increased screen time.

It is necessary to strengthen the knowledge base to make informed policies, guidelines, and treatments for reducing the adverse health impacts of screen time. Although digital screen time is a global issue, there is a lack of research on this topic from low- and middle-income countries. Therefore, strengthening collaborative research which engages global nations to combat common public health challenges associated with COVID-19 can improve international evidence and future practices ${ }^{33}$. Such collaborative research on the effects of screen time on diverse population groups would need multi-specialty research teams to better understand the epidemiological variances across populations. Moreover, leveraging digital technologies to assess behavioral dimensions and psychosocial correlates can be useful for generating user-level insights that may guide the development of future interventions ${ }^{34-36}$. Particularly, assessing dose-response relationships between screen time and health outcomes in different COVID-affected population groups may facilitate the development of informed practice guidelines.

Many studies during COVID-19, as well as in the pre-pandemic era, assessed screen time in children and younger populations ${ }^{11,37}$, which can be a research trend attributable to the fact that these populations are more vulnerable to increased screen time with lesser self-control and this is likely to have long-term consequences. Although screen-based activities in moderation pose no harm, children and teenagers often lack the discipline and insight to limit screen time on their own. It is essential to further specify the safe levels of screen time for age-specific groups through assessing available evidence and ensuring consensus among pediatricians, general practitioners, parents, teachers, 
social workers, and other key stakeholders. There is a growing body of evidence suggesting that the home environment also plays a vital role in screen time. The presence of a TV in the bedroom, lack of house rules for TV watching, and infrequent family meals are associated with increased duration of screen time ${ }^{14,38-41}$. Many studies have identified that setting house rules can be effective in limiting screen time for children. For example, a randomized control trial by Barr-Anderson et al., reported that a change in a parent's total screen time and parental rules limiting TV watching were associated with reduced screen time among the children in the study ${ }^{42}$. Similarly, Birken et al., found that eating lunch in front of the TV and an increase in parental screen time by one hour significantly increased children's screen time. However, a fixed time for screen time reduced hours spent in front of the TV by 30 minutes per day among children ${ }^{43}$. Additionally, $\mathrm{Hu}$ et al., reported that Chinese preschoolers belonging to households with regulations to limit screen time had improved social and cognitive skills. They also found that mothers hold a pivotal role in modeling children's screen behavior $^{44}$.

Parents can be instrumental in reducing screen time for children by ameliorating the overall environment of the house, improving family bonding, and regulating screen time. Although parents' role has become more critical during this COVID-19 pandemic, many are struggling to achieve a work-life balance as they must navigate working from home ${ }^{45-47}$. This struggle is more pronounced in lower-income families as they were hit disproportionately by the current catastrophe ${ }^{48}$. The government can mobilize resources to train and support parents to guide their children. Teachers and pediatricians can increase awareness among parents regarding screen time through social media campaigns, webinars, and other online forums. Training modules can be developed for parents to improve household regulation regarding screen time and better guide their children. Lastly, social workers and community health workers can also be employed to train parents and provide psychosocial support as necessary.

Similar approaches can be adopted for special population groups such as working professionals who may have similar patterns of screen use. Identifying such trends and the underlying psychosocial reasons associated with screen use may enable the development and adoption of common strategies addressing elevated screen time and associated health outcomes. In this regard, guidelines provided by the World Health Organization (WHO) and other institutions may offer some strategic directions regarding how existing guidelines should be revisited and used to develop future guidelines and recommendations. However, such efforts must consider COVID-related psychosocial factors and age-specific behavioral constructs for achieving optimal appropriateness.

The prevention of unhealthy screen use and associated health outcomes may require specific interventions that acknowledge the unique variances of the quantity and quality of different screen types. For instance, individuals watching television may have different screen use levels than those using social media in smart devices. Targeted interventions should emphasize delivering mass media and online-based health communications, focusing on diverse populations with varying screen time. Such segments of individuals with specific digital behavior may require personalized interventions for preventing unhealthy screen use. Additionally, place and population-specific limitations and opportunities for digital health technologies should be explored for optimal implementation of such intervention ${ }^{49,50}$. Strategies such as setting limits for screen-based educational or institutional activities complemented by planned exercises that involve offline communications and activities can be useful for people staying at home and attending online sessions ${ }^{51}$.

Both digitally and traditionally delivered interventions should aim not only to make people aware of the adverse consequences of screen time but also enable them to engage in active lifestyles, improved dietary practices, and healthier behaviors that promote individual health and wellbeing ${ }^{35,52}$. It would be necessary to create enabling environments at home or communities that may allow off-screen in-person physical and psychosocial activities that do not compromise safety measures related to COVID-19 while protecting individuals from an unhealthy lifestyle. Nonetheless, psychosocial interventions during COVID-19 should aim for improving social capital and community-level determinants of health that facilitate sustainable health and wellbeing ${ }^{53}$. Such interventions should be evidence-based and culturally appropriate, incorporating the perspectives of primary users, healthcare providers, and communities. Local, national, and global healthcare organizations and scientific societies may play critical roles by providing updated evidence and recommendations that should be widely communicated for developing multilevel strategies that promote healthier screen use choices for individuals and populations ${ }^{51,54}$.

\section{Conclusions}

COVID-19 has affected many aspects of human lives, including the patterns of digital screen use. Previous literature describes the varying levels of health impacts associated with screen time, whereas a growing number of recent studies have shown a rising trend of screen time in different populations with possible health impacts. Prospective research may provide further insights into how different types and amounts of screen time may influence health outcomes across populations. As different populations may have varying screen use behavior, and associated health outcomes, healthcare providers and decision-makers should emphasize on empowering those populations to adopt healthier lifestyles and behaviors. It is critical to use the available evidence and adopt multilevel measures for preventing unhealthy screen time and other behaviors that may impact health and wellbeing among individuals at risk.

\section{Data availability}

No data are associated with this article. 
1. Acter T, Uddin N, Das 」, et al: Evolution of severe acute respiratory syndrome coronavirus 2 (SARS-CoV-2) as coronavirus disease 2019 (COVID-19) pandemic: A global health emergency. Sci Total Environ J. 2020; 730: 138996. PubMed Abstract | Publisher Full Text | Free Full Text

2. Hossain MM, Tasnim S, Sultana A, et al.: Epidemiology of mental health problems in COVID-19: a review [version 1; peer review: 2 approved]. F1000Res. 2020; 9: 636 .

PubMed Abstract | Publisher Full Text | Free Full Text

3. Altmann DM, Douek DC, Boyton RJ: What policy makers need to know about COVID-19 protective immunity. Lancet. 2020; 395(10236): 1527-1529. PubMed Abstract | Publisher Full Text | Free Full Text

4. Kuguyo O, Kengne AP, Dandara C: Singapore COVID-19 Pandemic Response as a Successful Model Framework for Low-Resource Health Care Settings in Africa? OMICS. 2020; 24(8): 470-478. PubMed Abstract | Publisher Full Text

5. McKee M: Learning from success: how has Hungary responded to the COVID pandemic? GeroScience. 2020; 42(5): 1217-1219. PubMed Abstract | Publisher Full Text | Free Full Tex

6. Esposito S, Principi N, Leung CC, et al.: Universal use of face masks for success against COVID-19: evidence and implications for prevention policies. Eur Respir J. 2020; 55(6): 2001260.

PubMed Abstract | Publisher Full Text | Free Full Text

7. Robbins T, Hudson S, Ray P, et al.: CovID-19: A new digital dawn? Digit Health 2020; 6: 2055207620920083.

PubMed Abstract | Publisher Full Text | Free Full Text

8. Ting DSW, Carin L, Dzau V, et al.: Digital technology and COVID-19. Nat Med. 2020; 26(4): 459-461.

PubMed Abstract | Publisher Full Text | Free Full Text

9. Király O, Potenza MN, Stein DJ, et al.: Preventing problematic internet use during the COVID-19 pandemic: Consensus guidance. Compr Psychiatry. 2020; 100: 152180

PubMed Abstract | Publisher Full Text | Free Full Text

10. Wang $X, L i Y$, Fan $H$ : The associations between screen time-based sedentary behavior and depression: a systematic review and meta-analysis. $B M C$ Public Health. 2019; 19(1): 1524

PubMed Abstract | Publisher Full Text | Free Full Text

11. Janssen $X$, Martin A, Hughes AR, et al.: Associations of screen time, sedentary time and physical activity with sleep in under $5 \mathrm{~s}$ : A systematic review and meta-analysis. Sleep Med Rev. 2020; 49: 101226. PubMed Abstract | Publisher Full Text | Free Full Text

12. Kuss DJ, Griffiths MD: Internet and gaming addiction: a systematic literature review of neuroimaging studies. Brain Sci. 2012; 2(3): 347-74. PubMed Abstract | Publisher Full Text | Free Full Text

13. Lanca C, Saw SM: The association between digital screen time and myopia: A systematic review. Ophthalmic Physiol Opt. 2020; 40(2): 216-229. PubMed Abstract | Publisher Full Text

14. Górnicka M, Drywień ME, Zielinska MA, et al.: Dietary and Lifestyle Changes During COVID-19 and the Subsequent Lockdowns among Polish Adults: A Cross-Sectional Online Survey PLifeCOVID-19 Study. Nutrients. 2020; 12(8): 2324.

PubMed Abstract | Publisher Full Text | Free Full Text

15. Keel PK, Gomez MM, Harris L, et al.: Gaining “The Quarantine 15:" Perceived versus observed weight changes in college students in the wake of COVID19. Int J Eat Disord. 2020; 53(11): 1801-1808.

PubMed Abstract | Publisher Full Text | Free Full Text

16. Hu Z, Lin X, Kaminga AC, et al.: Impact of the COVID-19 Epidemic on Lifestyle Behaviors and Their Association With Subjective Well-Being Among the General Population in Mainland China: Cross-Sectional Study. J Med Internet Res. 2020; 22(8): e21176.

PubMed Abstract | Publisher Full Text | Free Full Text

17. Carroll N, Sadowski A, Laila A, et al.: The Impact of COVID-19 on Health Behavior, Stress, Financial and Food Security among Middle to High Income Canadian Families with Young Children. Nutrients. 2020; 12(8): 2352. PubMed Abstract | Publisher Full Text | Free Full Text

18. Ozturk Eyimaya A, Yalçin Irmak A: Relationship Between Parenting Practices and Children's Screen Time During the COVID-19 Pandemic in Turkey. Pediatr Nurs. 2021; 56: 24-29.

PubMed Abstract | Publisher Full Text | Free Full Text

19. Pišot S, Milovanović $\mathrm{I}$, Šimunič $\mathrm{B}$, et al.: Maintaining everyday life praxis in the time of COVID-19 pandemic measures (ELP-COVID-19 survey). Eur J Public Health. 2020; 30(6): 1181-1186.

PubMed Abstract | Publisher Full Text | Free Full Text

20. Majumdar P, Biswas A, Sahu S: COVID-19 pandemic and lockdown: cause of sleep disruption, depression, somatic pain, and increased screen exposure of office workers and students of India. Chronobiol Int. 2020; 37(8): 1191 1200.

PubMed Abstract | Publisher Full Text

21. Smith $L$, Jacob $L$, Trott $M$, et al.: The association between screen time and mental health during COVID-19: A cross sectional study. Psychiatry Res. 2020;
292: 113333

PubMed Abstract | Publisher Full Text | Free Full Text

22. Qin F, Song Y, Nassis GP, et al.: Physical Activity, Screen Time, and Emotional Well-Being during the 2019 Novel Coronavirus Outbreak in China. Int Environ Res Public Health. 2020; 17(14): 5170.

PubMed Abstract | Publisher Full Text | Free Full Text

23. Colley RC, Bushnik T, Langlois K: Exercise and screen time during the COVID19 pandemic. Health Rep. 2020; 31(6): 3-11. PubMed Abstract | Publisher Full Text

24. Xiao S, Yan Z, Zhao L: Physical Activity, Screen Time, and Mood Disturbance Among Chinese Adolescents During COVID-19.J Psychosoc Nurs Ment Health Serv. 2020; 1-7.

PubMed Abstract | Publisher Full Text

25. Hossain MM, Khan N, Sultana A, et al.: Prevalence of comorbid psychiatric disorders among people with autism spectrum disorder: An umbrella review of systematic reviews and meta-analyses. Psychiatry Res. 2020; 287: 112922.

PubMed Abstract | Publisher Full Text

26. Hossain MM, Sultana A, Tasnim S, et al.: Prevalence of mental disorders among people who are homeless: An umbrella review. Int J Soc Psychiatry. 2020: 66(6): 528-541.

PubMed Abstract | Publisher Full Text

27. Hossain MM: Umbrella Review as an Emerging Approach of Evidence Synthesis in Health Sciences: A Bibliometric Analysis. SSRN Electron J. 2020. Publisher Full Text

28. Fang $\mathrm{K}, \mathrm{Mu} \mathrm{M}$, Liu K, et al.: Screen time and childhood overweight/obesity: A systematic review and meta-analysis. Child Care Health Dev. 2019; 45(5): 744-753.

PubMed Abstract | Publisher Full Text

29. Guo C, Zhou Q, Zhang D, et al:: Association of total sedentary behaviour and television viewing with risk of overweight/obesity, type 2 diabetes and hypertension: A dose-response meta-analysis. Diabetes Obes Metab. 2020; 22(1): 79-90.

PubMed Abstract | Publisher Full Text

30. Stamatakis E, Hamer M, Dunstan DW: Screen-based entertainment time, allcause mortality, and cardiovascular events: population-based study with ongoing mortality and hospital events follow-up. J Am Coll Cardiol. 2011; 57(3): 292-299. PubMed Abstract | Publisher Full Text

31. Marker C, Gnambs T, Appel M: Exploring the myth of the chubby gamer: A meta-analysis on sedentary video gaming and body mass. Soc Sci Med. 2019; 112325.

PubMed Abstract | Publisher Full Text

32. Pfefferbaum B, Nitiéma P, Newman E: Is Viewing Mass Trauma Television Coverage Associated With Trauma Reactions in Adults and Youth? A MetaAnalytic Review. J Trauma Stress. 2019; 32(2): 175-185. PubMed Abstract | Publisher Full Text

33. Hossain MM: Current status of global research on novel coronavirus disease (COVID-19): a bibliometric analysis and knowledge mapping [version 1; peer review: 2 approved with reservations]. F1000Res. 2020; 9 : 374. Publisher Full Text

34. Ahasan R, Hossain MM: Leveraging GIS and spatial analysis for informed decision-making in COVID-19 pandemic. Health Policy Technol. 2020. PubMed Abstract | Publisher Full Text | Free Full Text

35. Sarbadhikari S, Sarbadhikari SN: The global experience of digital health interventions in COVID-19 management. Indian J Public Health. 2020; 64(Supplement): S117-S124 PubMed Abstract | Publisher Full Tex

36. Hossain MM, McKyer ELJ, Maa P: Applications of artificial intelligence technologies on mental health research during COVID-19. SocArXiv. 2020. Reference Source

37. Stiglic N, Viner RM: Effects of screentime on the health and well-being of children and adolescents: A systematic review of reviews. BMJ Open. 2019; 9(1): e023191.

PubMed Abstract | Publisher Full Text | Free Full Text

38. Gingold JA, Simon AE, Schoendorf KC: Excess screen time in US children Association with family rules and alternative activities. Clin Pediatr (Phila). 2014; 53(1): 41-50. PubMed Abstract | Publisher Full Text

39. Bauer KW, Neumark-Sztainer D, Fulkerson JA, et al: Familial correlates of adolescent girls' physical activity, television use dietary intake, weight and body composition. Int J Behav Nutr Phys Act. 2011; 8: 25. PubMed Abstract | Publisher Full Text | Free Full Text

40. Carlson SA, Fulton JE, Lee SM, et al.: Influence of limit-setting and participation in physical activity on youth screen time. Pediatrics. 2010; 126(1): e89-96.

PubMed Abstract | Publisher Full Text 
41. Sisson SB, Broyles ST, Newton RL, et al:: TVs in the bedrooms of children: Does it impact health and behavior? Prev Med. 2011; 52(2): 104-8. PubMed Abstract | Publisher Full Text

42. Barr-Anderson DJ, Fulkerson JA, Smyth M, et al.: Associations of American Indian children's screen-time behavior with parental television behavior, parental perceptions of children's screen time, andmedia-related resources in the home. Prev Chronic Dis. 2011; 8(5): A105. PubMed Abstract | Free Full Text

43. Birken CS, Maguire J, Mekky M, et al.: Parental factors associated with screen time in pre-school children in primary-care practice: A TARGet Kids! study. Public Health Nutr. 2011; 14(12): 2134-2138. PubMed Abstract | Publisher Full Text

44. Hu BY, Johnson GK, Wu H: Screen time relationship of Chinese parents and their children. Child Youth Serv Rev. 2018; 94: 659-669. Publisher Full Text

45. Davis CR, Grooms J, Ortega A, et al.: Distance Learning and Parental Mental Health During COVID-19. Educ Res. 2020; 50(1): 61-64. Publisher Full Text

46. Hjálmsdóttir A Bjarnadóttir VS. “I have turned into a foreman here at home." Families and work-life balance in times of Covid-19 in a gender equality paradise. Gender Work Organ. 2020. PubMed Abstract | Publisher Full Text | Free Full Text

47. Garbe A, ogurlu U, Logan N, et al.: Parents' Experiences with Remote Education during COVID-19 School Closures. Am J Qual Res. 2020; 4(3): 45-65. Publisher Full Text
48. Dooley DG, Bandealy A, Tschudy MM: Low-Income Children and Coronavirus Disease 2019 (COVID-19) in the US. JAMA Pediatr. 2020; 174(10): 922-923. PubMed Abstract | Publisher Full Text

49. Hossain MM, Tasnim S, Sharma R, et al.: Digital interventions for people living with non-communicable diseases in India: A systematic review of intervention studies and recommendations for future research and development. Digit Health. 2019; 5: 2055207619896153. PubMed Abstract | Publisher Full Text | Free Full Text

50. Ahasan R, Alam MS, Chakraborty T, et al.: Applications of GIS and geospatial analyses in COVID-19 research: A systematic review [version 1; peer review: awaiting peer review]. F1000Res. 2020; 9: 1379. Publisher Full Text

51. Wiederhold BK: Children's Screen Time During the COVID-19 Pandemic: Boundaries and Etiquette. Cyberpsychol Behav Soc Netw. 2020; 23(6): 359-360. PubMed Abstract | Publisher Full Text

52. Duan L, Zhu G: Psychological interventions for people affected by the COVID-19 epidemic. Lancet Psychiatry. 2020; 7(4): 300-302 PubMed Abstract | Publisher Full Text | Free Full Text

53. Rodela TT, Sultana A, McKyer ELJ, et al: Social capital and mental health during the COVID-19 pandemic. SocArXiv. 2020;1-7. Reference Source

54. Nagata JM, Abdel Magid HS, Pettee Gabriel K: Screen Time for Children and Adolescents During the Coronavirus Disease 2019 Pandemic. Obesity (Silver Spring). 2020; 28(9): 1582-1583.

PubMed Abstract | Publisher Full Text | Free Full Text 


\section{Open Peer Review}

\section{Current Peer Review Status:}

\section{Version 1}

Reviewer Report 09 May 2022

https://doi.org/10.5256/f1000research.53970.r126292

(C) 2022 Tamana S et al. This is an open access peer review report distributed under the terms of the Creative Commons Attribution License, which permits unrestricted use, distribution, and reproduction in any medium, provided the original work is properly cited.

\section{Sukhpreet Tamana}

Faculty of Health Sciences, Simon Fraser University, Burnaby, BC, Canada

\section{Victor Ezeugwu}

Departments of Pediatrics, University of Alberta, Edmonton, AB, Canada

This is an important and timely synthesis of data reporting on a topic of growing concern around screen time use and associated risk of health problems in the context of the COVID-19 pandemic. The authors summarize in this unsystematic narrative review, the prevalence and average duration of screen time exposure across different populations during the COVID-19 pandemic. The article also describes evidence assessing associations between screen time and various health outcomes and proposes potential mitigation strategies. The article is clearly written and generally well organized.

A few considerations that the authors may consider:

\section{Major points to consider}

It is important for the authors to explain and describe available screen time recommendation guidelines developed for adults and children (for example the American Academy of Pediatrics, Canadian 24-Hour Movement Guidelines). This would be helpful to the reader when interpreting the studies of screen time exposure the authors summarize in this paper.

The authors interpretation or synthesis of the data does not consider any differences between studies such as populations sampled, sample size, adjustment for covariates, and differences in study design and how screen time was assessed (e.g., total number of hours, range). This could be addressed as a section explicitly stating any limitations.

\section{Minor points to consider}

1. Title

We suggest the authors include "narrative review" or at a minimum "review" in the title.

\section{Abstract}


Consider replacing the term "a higher number" with "a higher percentage."

3. Introduction

In the second paragraph, the authors explain how the articles were retrieved but do not indicate the time frame. Please clarify the text as follows "..from available articles retrieved between XX and XX from Medline..".

The scope of the literature search appears to be limited. Other databases beyond Google Scholar and Medline should have been included. Please clarify.

In the second paragraph, line 3, consider rephrasing "problems in COVID-19" to "the associated problems with the COVID-19 pandemic".

4. Discussion

Section 'COVID-19 and rising trends of screen time: public health concerns": Paragraph 1, reference number 18 appears to be the incorrect citation. Please amend.

Section 'Global evidence on the association between screen time and health outcomes': Here the authors summarize data from studies conducted pre-pandemic. We suggest removing the term 'global' from the title and/or replace it with the term "preCOVID-19 or pre-pandemic".

The authors should indicate any limitations. Were all the studies identified of high or moderate quality?

5.Conclusions:

In the text "...those populations to adopt healthier lifestyles and behaviors." Consider replacing "healthier lifestyles and behaviors" with "healthier screen time use."

Is the topic of the review discussed comprehensively in the context of the current literature?

Yes

Are all factual statements correct and adequately supported by citations?

Yes

Is the review written in accessible language?

Yes

Are the conclusions drawn appropriate in the context of the current research literature? Partly

Competing Interests: No competing interests were disclosed.

Reviewer Expertise: Mental health, screen time, sleep, behavioral health, physical health, sedentary behavior, epidemiology, interventions.

We confirm that we have read this submission and believe that we have an appropriate level of expertise to confirm that it is of an acceptable scientific standard, however we have significant reservations, as outlined above. 
Reviewer Report 09 May 2022

https://doi.org/10.5256/f1000research.53970.r136401

(C) 2022 Johnson Jr. M. This is an open access peer review report distributed under the terms of the Creative Commons Attribution License, which permits unrestricted use, distribution, and reproduction in any medium, provided the original work is properly cited.

\section{Michael Johnson Jr.}

California State University, Northridge, CA, USA

The author offers an interesting analysis about the impact of screen time exposure on the physical and mental condition of people pre-pandemic. It ties the residential captivity of populations due to the COVID-19 epidemic, with the pre-existing co-morbidities which often accompany sedentary media consumption. "...the closure or remote operations of schools, offices, and other organizations have resulted in higher use of digital media such as desktops, laptops, tablet computers, and mobile devices for interpersonal communications" and it links previous research which demonstrated increased screen time with "a wide range of non-communicable diseases among vulnerable individuals".

To accomplish this task the authors conducted a meta-analysis of the extant literature, despite a very limited number of studies on the subject. Importantly the authors conclude that remedies to screen time consumption "may require specific interventions that acknowledge the unique variances of the quantity and quality of different screen types...It would be necessary to create enabling environments at home or communities that may allow off-screen in-person physical and psychosocial activities that do not compromise safety measures related to COVID-19 while protecting individuals from an unhealthy lifestyle". The authors make a number of cogent observations which are informed by the research examples they utilize to good effect. Its conclusions are sound and limited to specifics that recognize different levels of media consumption across a variety of viewing demographics and amidst wide disparities in global healthcare.

The only issue with the authors' narrative is the numerical inconsistency between what they describe as limited research on the subject with 195 (by my count) studies reviewed in their research. They should make a disclaimer to clarify how these two seemingly disparate facts can exist simultaneously. Despite this minor reservation, I believe the article provides a useful starting point that expands upon the literature of media consumption and therefore I can recommend indexing. As I note in my recently published 2021 article on the subject" , "There's no question that an important percentage of domestic American consumers are interested in the a la carte consumption habits, ease of accessibility (especially on mobile devices), and demand for "original" content, streaming will continue to have an appeal" and this observation has significance for the author's contention that screen time correlates with increased comorbidities that endanger the population's public health during the pandemic. If streaming does increase in popularity, as I fully anticipate that it will, then the screen time consumption dynamic the authors have identified will become even more concerning as time under COVID 19 continues.

\section{References}


1. Johnson M: Hollywood survival strategies in the post-COVID 19 era. Humanities and Social Sciences Communications. 2021; 8 (1). Publisher Full Text

Is the topic of the review discussed comprehensively in the context of the current literature?

Yes

Are all factual statements correct and adequately supported by citations? Yes

Is the review written in accessible language?

Yes

Are the conclusions drawn appropriate in the context of the current research literature? Yes

Competing Interests: No competing interests were disclosed.

Reviewer Expertise: Television; Political Economics; Media Industries; LGBTQ; Race \& Ethnicity I confirm that I have read this submission and believe that I have an appropriate level of expertise to confirm that it is of an acceptable scientific standard.

The benefits of publishing with F1000Research:

- Your article is published within days, with no editorial bias

- You can publish traditional articles, null/negative results, case reports, data notes and more

- The peer review process is transparent and collaborative

- Your article is indexed in PubMed after passing peer review

- Dedicated customer support at every stage

For pre-submission enquiries, contact research@f1000.com 